\title{
The Influences of the Presence of Ions Counter on the Removal Capacity Fluorides lons by Chitosane
}

\author{
S. ANNOUAR ${ }^{1,2}$, A. MOUFTI ${ }^{\star 1,3}$, S. MOUNTADAR ${ }^{1}$, \\ M. MOUNTADAR ${ }^{1}$ and ET A. SOUFIANE ${ }^{2}$ \\ 'Laboratory of Water and Environment.PB: 20, P.C: 24000 . Faculty of Science.El Jadida. Morocco \\ ${ }^{2}$ Laboratory of analytical chemistry and coordination. PB: 20, P.C: 24000. \\ Faculty of Science.El Jadida. Morocco. \\ ${ }^{3}$ Regional Center for Careers in Education and Training. Settat. Morocco. \\ *Corresponding author E-mail: amoufti@gmail.com \\ http://dx.doi.org/10.13005/ojc/320145
}

(Received: November 30, 2015; Accepted: February 04, 2016)

ABSTRACT

To approximate conditions defluoridation groundwater, during this work, we are interested in the study of the influence of the presence of ions -counter on the ability of removing fluoride ions by chitosan. Also we searched the optimal conditions for the desorption using a basic solution. In light of this study, we observed that $\mathrm{NO}_{3}^{-}$and $\mathrm{HCO}_{3}$ - share are the real competitors to the removal of fluoride on chitosan. And secondly, Desorption of fluoride from saturated support is possible and efficient with the addition of $\mathrm{NaOH}$ in our optimal desorption conditions.

Key word: Ions counter, Chitosan, Defluoridation, Desorption, Ground Water.

\section{INTRODUCTION}

Polysaccharides are polymers of sugar units compounds in their cyclic form. They are naturally present under innumerable structures and compositions. Chitosan is one of these biopolymers. It is generally derived from chitin. Apart from cellulose, chitin is the most abundant biopolymer on Earth. The estimates of the abundance of chitin in the biosphere are about $10^{13} \mathrm{~kg}^{1}$. A large proportion of the chitin biosynthesis is of marine origin, or around $2.3 \times 10^{9} \mathrm{~kg}$ per year ${ }^{2}$ Chitin and chitosan are examples of non-biodegradable polymers and oil $^{3}$. These biopolymers are at the heart of the study subjects of several research groups. The number of scientific papers dealing with these polysaccharides has more than tripled over the last discovred, from 505 for 1995 to more than 1,800 publications in 2005 (source: ISI Web of Knowledge). The motivations that guide the choice of subjects of these research teams are many. The increasing interest in these substances is due to several factors: availability, architecture, cost and primarily, the potential they represent for a multitude of applications in various domains. Just to list a few, include water treatment, materials, food processing, biotechnology, chemical catalysis, filling chromatographic columns and the pharmaceutical industry ${ }^{1,4,5,6}$. 
Water available in nature contains many soluble or suspended substances, some of which may contain fluoride at very variable concentrations from one region to another. Indeed, groundwater from the phosphates regions such as Youssoufia and Khouribga are particularly rich in fluorides due to leaching of these rocks ${ }^{7,8}$.

The increase in the fluoride concentration in drinking water, causing a reduction of dental caries and prevention of tooth ename $1^{9,10}$ because fluoride is beneficial in small quantities but toxic in large doses ${ }^{11}$. The acute toxicity appears only at doses in the range of 2.5 to $5 \mathrm{~g}$ adsorbent ${ }^{12}$, as strong fluorosis rapid and often fatal. Chronic fluorosis, which develops over several months or even years, appear at concentrations above $2 \mathrm{mg} / \mathrm{l}$ of a mottled enamel is known from "Darmous" 13,14 . Before these permanent risks, defluoridation high concentration of waters in these cases F- becomes an obligation. Various methods have been tested for defluoridation water include: coagulation-flocculation and adsorption $8,15,16$, precipitation ${ }^{17}$, ion exchange, reverse osmosis and electrodialysis ${ }^{18-20}$.

The objective of this work is on the one hand, to study the effect of the presence of ions against the fluoride removal capacity of a synthetic solution by adsorption on chitosan. And secondly, to determine the optimal conditions for their desorption.

\section{MATERIALS AND METHODS}

\section{Preparation of adsorbents brute chitin}

Waste shrimps containing the soft part, head and shell are washed with distilled water and are then placed in an incubator at $50^{\circ} \mathrm{C}$ until total drying. These are then ground and washed several times with distilled water until neutral. After filtration,

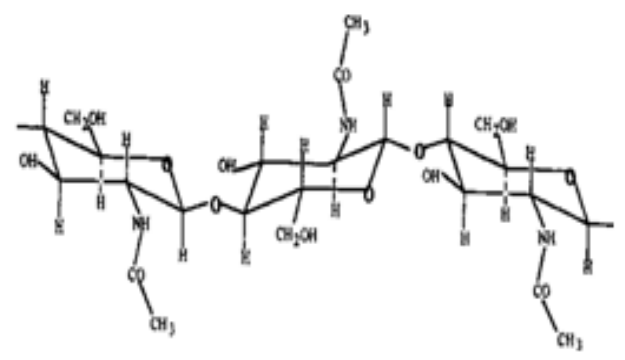

Fig. 1: Chemical structure of chitin. they are delivered to the oven at $50{ }^{\circ} \mathrm{C}$ for drying and storage. It must dry at $50{ }^{\circ} \mathrm{C}$ for not changing the structure of the organic fraction of the waste and this until a constant mass ${ }^{4,21}$.

\section{Chitin}

Chitin is a copolymer of D-glucosamine repeating units and $\mathrm{N}$-acetyl $\mathrm{D}$-glucosamine linked $\beta$ $(1 \rightarrow 4)$, whose chemical structure is shown in Figure 1. It is prepared by the method used in K. Ryachi ${ }^{21}$ crustacean wastes are first ground to have sizes of uniform particle $(\theta<710$ microns), are then soaked in a sodium hydroxide bath to $3 \%$ maintained at 50 ${ }^{\circ} \mathrm{C}$ in order to remove remaining proteins. Another bath of hydrochloric acid $(1.25 \mathrm{M})$ at $20^{\circ} \mathrm{C}$, removes calcium phosphate salts or which cause the hardness of the shell.

\section{Chitosan}

Chitosan, deacetylated chitin derived, is a linear copolymer $\beta$ - $(1 \rightarrow 4) \mathrm{N}$-acetyl D-glucosamine and D-glucosamine as shown in Figure 2. It is obtained after deacetylation of chitin. The deacetylation is a delicate stage, deacetylation technics utilize basic hydrolysis step in aqueous solution. This is the method most common pre-repair, which involves soaking chitin already prepared in a bath of $\mathrm{NaOH} 50 \%$ at $100^{\circ} \mathrm{C}$ for a period of 4 hours under mechanical agitation ${ }^{22,23}$.

At this point, when the product obtained is not enough white or lightly colored, we do a bleaching for one hour in an oxygenated water bath in acid $(\mathrm{HCl} /$ $\left.\mathrm{H}_{2} \mathrm{O}_{2}: 1 / 9: \mathrm{V} / \mathrm{V}\right)^{22,23}$. The last step of preparation is to wash chitosan obtained with distilled water several times until neutral $\mathrm{pH}$.

The characterization of adsorbent materials by physico-chemical techniques ( $R X, I R, \ldots)$ confirms that we have obtained chitin and chitosan ${ }^{24-26}$.

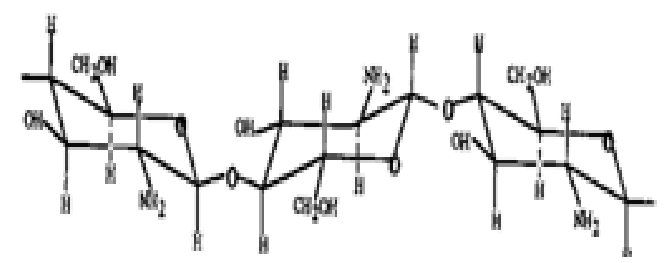

Fig. 2: Chemical structure of chitosan 
Preparation of the synthetic solution

A mother solution of each ion $\left(\mathrm{CO}_{3}{ }^{2-}\right.$, $\mathrm{NO}_{3}{ }^{-}, \mathrm{F}^{-}, \mathrm{SO}_{4}{ }^{2-}$ et $\left.\mathrm{Cl}^{-}\right)$was prepared from the mineral substance in the most soluble form $\left(\mathrm{Na}_{2} \mathrm{CO}_{3}, \mathrm{KNO}_{3}\right.$, $\mathrm{Na}_{2} \mathrm{SO}_{4}, \mathrm{NaF}$ et $\mathrm{NaCl}$ ) (product Merck purity 99\%), and test solutions are obtained by diluting the mother solution.

\section{Fluoride dosage}

For dosing fluorides, several methods can be used including titrimetry, spectrometry and fluorine activation analysis.

In our study, the fluoride was measured by the potentiometric method using TISAB solution, a specific electrode for fluoride ions and a reference electrode $(\mathrm{Ag} / \mathrm{AgCl})$. It has the advantage of being simple, rapid response and to lend to dosages ${ }^{27}$ according to the French standard AFNOR standard methods ${ }^{24}$ (AFNOR T90- 004). The apparatus used is a type of $\mathrm{pH}$-iconometerJENCO 6209 model with a specific fluoride electrode. The concentration range that can be measured is $510^{-7} \mathrm{M}$ to $1 \mathrm{M} \mathrm{F}^{-}$.

\section{pH measurement}

The $\mathrm{pH}$ of the solutions was measured using a WTW pH 522 meter with a combination electrode. Before each use, the device is calibrated using two Beckman buffers around the value to be measured $^{28}$.

\section{Defluoridation}

The adsorption experiments were carriedout, in batch wise, in aqueous solution to chitosan. We introduced into the beaker containing synthetic solution to be treated, a known quantity of chitosan.

The assembly is subjected to mechanical agitation and samples were taken over time $(t=15$ $\mathrm{min})$, the samples are stored in the refrigerator at 4 ${ }^{\circ} \mathrm{C}$ in plastic bottles. Analyses are performed within 24 hourswhich follow.

\section{RESULTS AND DISCUSSION}

Our study represents a continuation of our previous work concerning the defluoridation by various techniques, especially adsorption on chitosan, achieved by Annouar and $\mathrm{al}^{4,29}$, the optimum adsorption conditions are:

The stirring speed is $750 \mathrm{r} / \mathrm{min}$.

The better adsorption is obtained under ambient conditions $\mathrm{T}=20^{\circ} \mathrm{C}$.

The optimal of the adsorption is obtained in a slightly acidic medium ( $\mathrm{pH}=6)$.

The concentration of the adsorbent in the order of 4 $\mathrm{g} / \mathrm{l}$ gives a better yield.

The elimination reached $61 \%$ at a concentration of $8 \mathrm{mg} / \mathrm{l}$ of fluoride.

The Contact time with the support is of the order of 15 minutes.

Later, working in these preset conditions and adjust the $\mathrm{pH}$ of the solution to be treated to 6 before the addition of the adsorbent, meaning that we consider the interference between different ions present in the solution.

\section{Effect of the presence of ions against the defluorination}

To approximate conditions of groundwater, it is necessary to know if the presence of against-ion has an influence on the adsorption of fluoride which not. It is not obviously consider all the anions of water that exist in nature; for it is made of adsorption tests on certain ions which may compete with the adsorption of $\mathrm{F}$ and at the same time with the main compositions of natural water for varying ratios of $\left[\mathrm{F}^{-}\right] /$ $[\mathrm{X}]$ with $\mathrm{X}: \mathrm{Cl}^{-}, \mathrm{CO}_{3}{ }^{2-}, \mathrm{SO}_{4}{ }^{2-} \mathrm{ou} \mathrm{NO}_{3}{ }^{-}$et $[\mathrm{F}]=10 \mathrm{mg} / \mathrm{l}$.

\section{Effect of the presence of chloride ions}

The defluoridation curve in the presence of only fluoride ions increases with increasing concentration of fluoride to a maximum, to $60 \%$ at

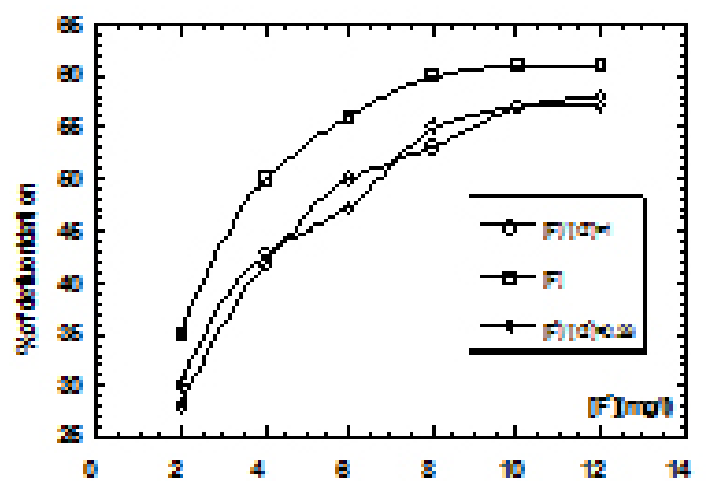

Fig. 3: Effect of the presence of chloride ion ( $\mathrm{pH}=6, \mathrm{~m}=4 \mathrm{~g} / \mathrm{l}, \mathrm{T}=20^{\circ} \mathrm{C}$ and $\mathrm{V}=750 \mathrm{tr} / \mathrm{min}$ ) 
$10 \mathrm{mg} / \mathrm{l}$ of $\mathrm{F}$. We can note that the defluoridation in the presence of $\mathrm{Cl}$, for different reports $\mathrm{F} / \mathrm{Cl}$, has an almost similar evolution, allowing us to say that the chloride ions have no significant effect on fluoride removal figure 3.

\section{Effect of the presence of sulfate ions}

Is also noted that, after the addition of sulfate ions to the various reports, the curve is similar

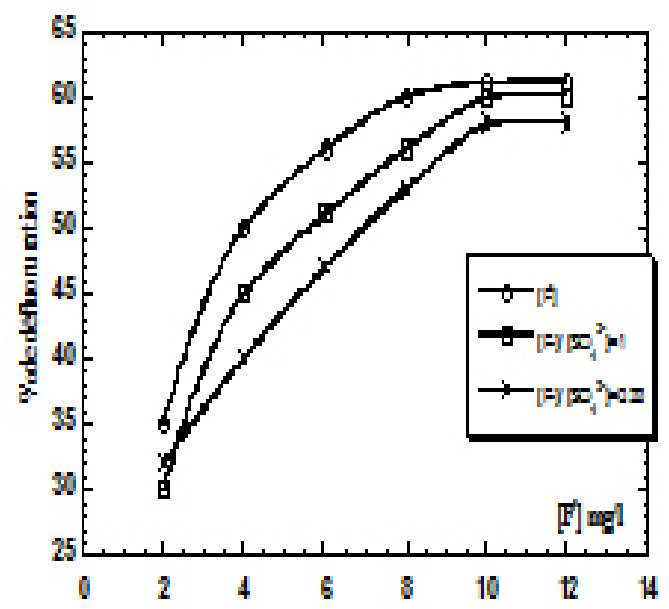

Fig. 4: Effect of the presence of sulfate ions $\left(\mathrm{pH}=6, \mathrm{~m}=4 \mathrm{~g} / \mathrm{l}, \mathrm{T}=20^{\circ} \mathrm{C}\right.$ and $\mathrm{V}=750 \mathrm{tr} / \mathrm{min}$ )

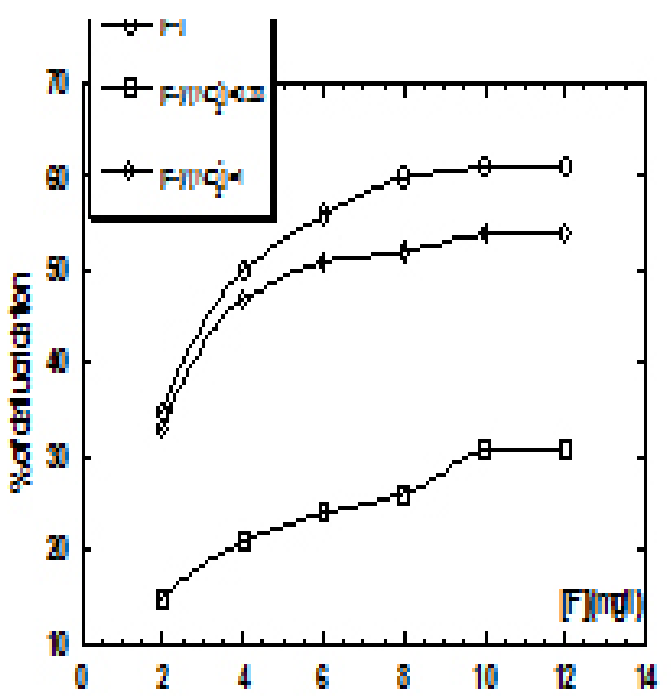

Fig. 5: Effect of the presence of nitrate ions $\left(\mathrm{pH}=6, \mathrm{~m}=4 \mathrm{~g} / \mathrm{l}\right.$ and $\mathrm{T}=20^{\circ} \mathrm{C}$ and $\mathrm{V}=750 \mathrm{tr} /$ $\min ) 1.4$. Effect of the presence of carbonate ions to that of fluoride alone. It can be concluded that the fluoride adsorption is a little influenced by the presence of sulfate ions. Therefore, the defluoridation is not influenced by the presence of sulfate ions at different doses.

\section{Effect of the presence of nitrate ions}

By comparing thedefluoridation curves of chitosan in the presence of fluorides and nitrates at different ratios and the defluoridation curve in the presence ofsole fluoride ions, one can say that for low concentrations of nitrates and fluorides, fluorine is adsorbed first. Firstly, the defluoridation capacity decreases when the dose of nitrate increases. And therefore the nitrate ions have very high towards the competitiveness of defluoridation especially for high concentrations.

\section{Effect of the presence of carbonate ions}

By analyzing defluoridation curves in the presence of carbonates, we note that for equal concentrations of $\mathrm{F}^{-}$and $\mathrm{CO}_{3}{ }^{2-}$, chitosan prefers fix $\mathrm{F}^{-}$. However, the removal percentage of fluoride decreases when the amount of introduced carbonate increases. This allows to say that the carbonate ion present high towards competitiveness of the removal of fluoride ions by chitosan, and in particular to high doses of carbonate ions.

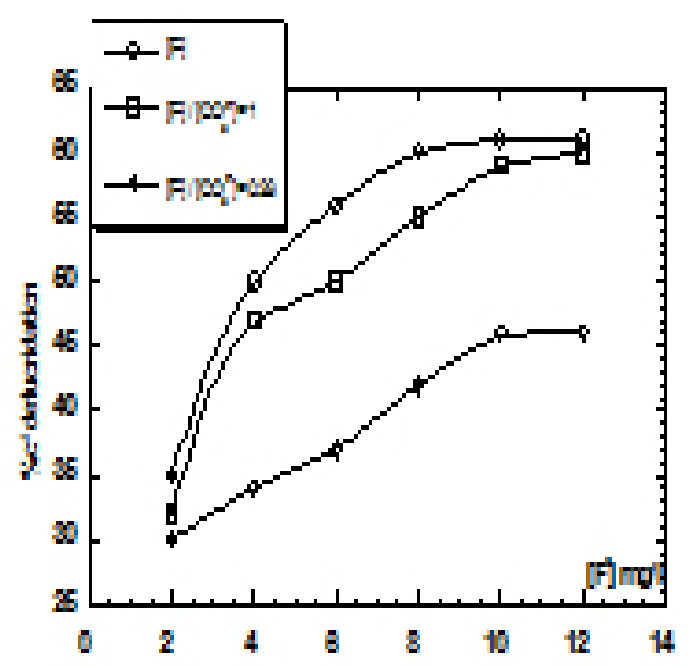

Fig. 6: Effect of the presence of carbonate ions $\left(\mathrm{pH}=6, \mathrm{~m}=4 \mathrm{~g} / \mathrm{l}, \mathrm{T}=20^{\circ} \mathrm{C}\right.$ et $\left.\mathrm{V}=750 \mathrm{tr} / \mathrm{min}\right)$ 
In intermediate acidic media, carbonates spontaneously transform into bicarbonates according to the equilibrium:

$$
\mathrm{CO}_{3}^{2-}+\mathrm{H}^{+} \leftrightarrow \mathrm{HCO}_{3}^{-} \text {pka }=10,35
$$

This allows us to write

$$
\left[\mathrm{HCO}_{3}^{-}\right] /\left[\mathrm{CO}_{3}^{2-}\right]=\left[\mathrm{H}^{+}\right] . \mathrm{Ka}=4.4711 .101<<
$$

In our working conditions, training of hydrogen carbonates is negligible, and therefore is interested in carbonates and not the adsorption of hydrogencarbonates.

\section{Interpretation}

Under the conditions studied, the results show that the presence of $\mathrm{Cl}^{-}$and $\mathrm{SO}_{4}{ }^{2-}$ not significantly affect the adsorption capacity for the different concentrations of these ions, unlike $\mathrm{CO}_{3}{ }^{2-}$ and $\mathrm{NO}_{3}{ }^{-}$ions that represent strong competitiveness towards the adsorption of fluoride by chitosan, especially for high concentrations. These results confirm those obtained by Jaafari and al in $1998^{30}$.

All based on the theory, it may explain the difference in selectivity for adsorption of ions competitive by comparison there of with a thermochemical ray.

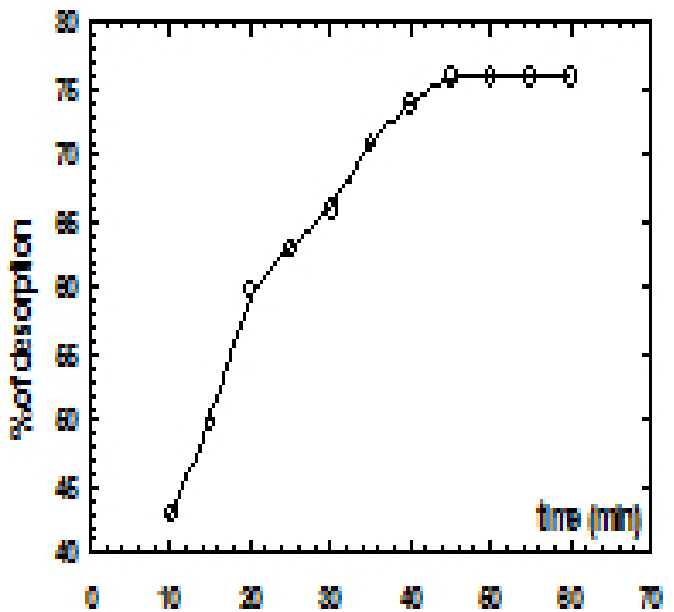

Fig. 7: The desorption kinetics fluoride ions ( $\mathrm{m}$ $=4 \mathrm{~g} / \mathrm{I},[\mathrm{NaOH}]=4 \mathrm{M},[\mathrm{F}]=10 \mathrm{mg} / \mathrm{l}, \mathrm{V}=250 \mathrm{tr} /$ $\min$ and $\mathrm{T}=20^{\circ} \mathrm{C}$ ).
The classification of these entities based on their thermochemical rays, given by Bernard et al in $1996^{31}$ respect the following order: $\mathrm{SO}_{4}{ }^{2-}(0.258$ $\mu \mathrm{m})>\mathrm{Cl}^{-}(0.177 \mu \mathrm{m})>\mathrm{NO}_{3}{ }^{-}(0.169 \mu \mathrm{m})>\mathrm{CO}_{3}{ }^{2-}(0.156$. $\mu \mathrm{m})>\mathrm{F}^{-}(0.126 \mu \mathrm{m})$. During the first reading of this classification, we can understand that the selectivity of the chitosan is not done by chance, but it's based on the size of the entity to be adsorbed. We can therefore conclude that the selectivity of chitosan is based on the important parameter that is the thermochemical ray of the hydrated ion and taking into account the stability of coordination compounds obtained.

\section{Desorption of the fluoride with sodium hydroxide}

In principle anything that does not favor the adsorption can involve desorption ${ }^{32}$. The defluoridation is significantly related to the $\mathrm{pH}$, which is why we made a regeneration with sodium hydroxide (soda).

The investigation of the desorption of fluoride was made of parameter values that encourage desorption: concentration of soda, the volume of implementing and desorption kinetics.

Desorption tests were carried on the quantity of chitosan that has been saturated by contact with water rich in fluoride $(10 \mathrm{mg} / \mathrm{l})$. Desorption consists in

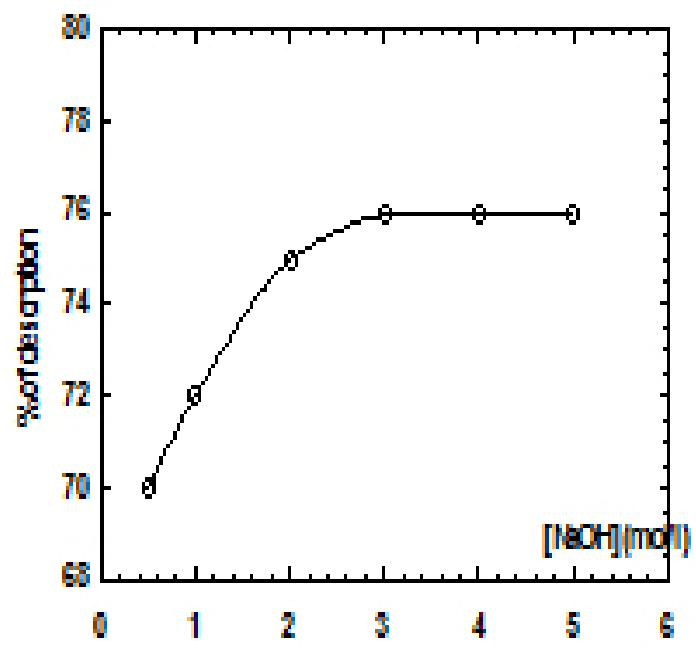

Fig. 8: Effect of soda concentration on the desorption 
putting in contact, the saturated support fluorides with a basic solution for one hour, and then measuring the concentration of fluoride in the solution.

\section{Kinetics of desorption}

- Preliminary tests to determine the minimum time of desorption are using:

- $10 \mathrm{~g}$ saturated support fluorides.

- $100 \mathrm{ml}$ of sodium hydroxide solution (4 M).

- $\quad$ Agitation at $250 \mathrm{tr} / \mathrm{min}$ for different durations.

- Finally, the solutions were analyzed after filtration.

It is noted that the maximum desorption is reached after 45 minutes with a desorption capacity equal to $76 \%$ (Figure 7 ).

\section{Effect of soda concentration on the desorption}

To determine the optimum concentration of soda, the desorption is carried out according to the same previous protocol, but with varying concentrations of sodium hydroxide.

We note that according to Figure 8 desorption is fast and efficient even for low concentrations of $\mathrm{NaOH}$. The optimum desorption $(76 \%)$ is obtained for higher soda concentrations $([\mathrm{NaOH}]=3 \mathrm{M})$.

\section{Efficiency of desorption for different volumes in sodium hydroxide solution}

The optimal volume of the sodium hydroxide solution required for the maximum desorption is determined following the same protocol taking into account the optimum concentration and the predetermined contact time.

The maximum desorption is reached from a volume of $50 \mathrm{ml}$ of $3 \mathrm{M}$ sodium hydroxide solution. Indeed, the percentage of desorption is constant when the volume is more than $50 \mathrm{ml}$.

\section{Cycles adsorption-desorption}

$10 \mathrm{~g}$ of chitosan are bet in contact with a solution containing $10 \mathrm{mg}$ I of fluoride, with an agitation speed of $750 \mathrm{tr} / \mathrm{min}$ and at a $\mathrm{pH}$ of 6 . After 15 minutes of contact, the support is separated into

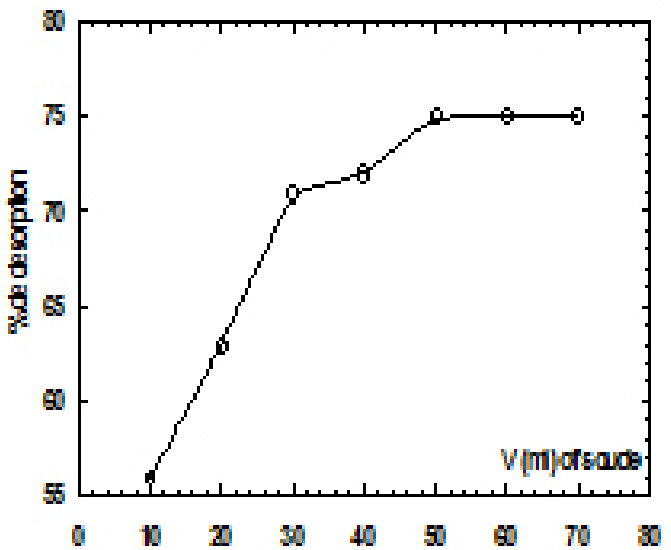

Fig. 9: Desorption efficiency for different volumes of soda $(\mathrm{m}=\mathbf{4} \mathrm{g} / \mathrm{I}$, [NaOH] $=3 \mathrm{M}$, [F-] $=10 \mathrm{mg} / \mathrm{l}, \mathrm{V}=250 \mathrm{tr} / \mathrm{min}$ and $\mathrm{T}=20^{\circ} \mathrm{C}$ ).

\section{$\%$ of desorption}

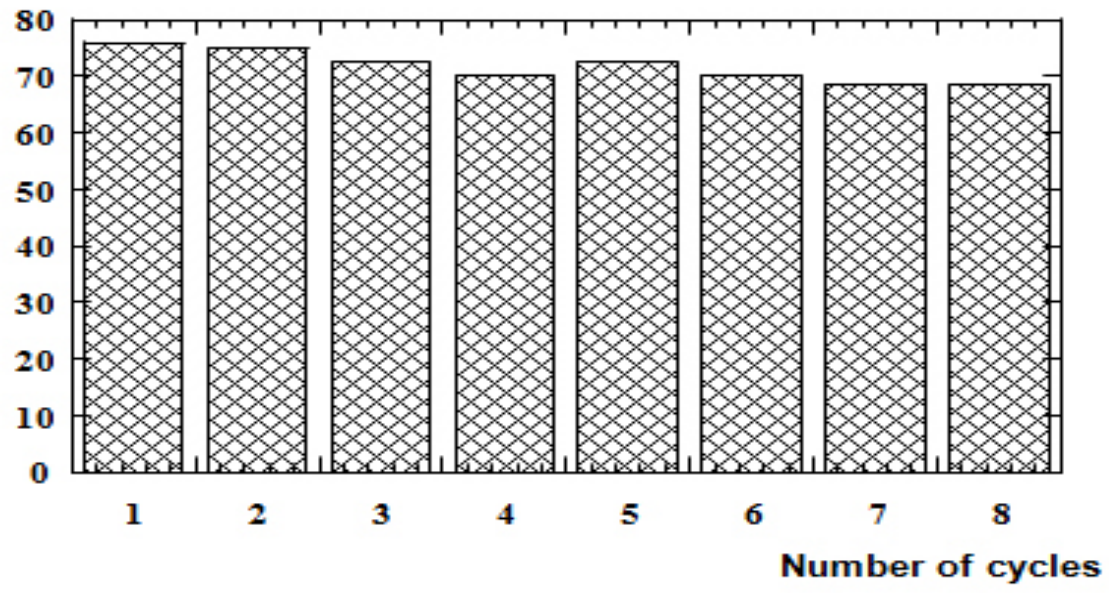

Fig. 10: Fluoride desorption rate of 8 adsorption-desorptioncycles performed. 
a basic solution of $100 \mathrm{ml}$ of $\mathrm{NaOH}(3 \mathrm{M}$ ) of $250 \mathrm{tr} /$ min. After 45 minutes of desorption the support is recovered by filtration and is washed more than once it is readjust the $\mathrm{pH}$ with a $\mathrm{HCl}$ solution at 6 and the next adsorption phase can start again.

The representation of the results as a histogram of the percentage desorption depending on the number of cycles performed, revealed that the fluoride desorption rates from chitosan saturated with fluorides, is practically constant for 8 cycles performed.

\section{DISCUSSION}

In slightly acidic medium, one obtains a protonation of the organic functions present in the chitosan structure and the charge of the formed complex is compensated by the fixing of fluoride according to the following reaction:

$$
\mathrm{RCH}_{2}-\mathrm{NH}_{2}+\mathrm{H}^{+} \leftrightarrow \mathrm{RCH}_{2}-\mathrm{NH}_{3}^{+}
$$

The removal of fluoride is done there after according to the following reaction:

$$
\mathrm{RCH}_{2}-\mathrm{NH}_{3}^{+}+\mathrm{F} \leftrightarrow\left(\mathrm{RCH}_{2}-\mathrm{NH}_{3}{ }^{+}, \mathrm{F}^{-}\right)
$$

The addition of a strong base to the complex formed allows the neutralization of this and therefore the release of nitrates by the following reaction:

$$
\begin{gathered}
\left(\mathrm{RCH}_{2}-\mathrm{NH}_{3}{ }^{+}, \mathrm{F}-\right)+\mathrm{OH}^{-} \leftrightarrow \mathrm{RCH}_{2}-\mathrm{NH}_{2}+\mathrm{H}_{2} \mathrm{O}+\mathrm{F}^{-} \\
\text {CONCLUSION }
\end{gathered}
$$

\section{CONCLUSION}

In light of this study competitiveness of the against-ions with respect to the elimination of fluorides depends thermochemical ray of the hydrated ion considered. Indeed $\mathrm{NO}_{3}{ }^{-}$and $\mathrm{HCO}_{3}$ are the real competitors to the removal of fluoride on chitosan.

concentration of ions against moves the equilibrium to the fixing against ions and the fluoride release.

Desorption of fluoride from saturated support is possible and efficient with the addition of $\mathrm{NaOH}$ in our optimal desorption conditions. Indeed the addition of the strong base to the complex formed after the defluoridation allows the neutralization of the latter and therefore the release of fluoride. In order to reduce the cost of the desorption of chitosan, it seems more discriminant using natural strong base which is more economical than lime. Can also valoriz the chitosan after saturation of fluorides as a fertilizer in agriculture.

\section{REFERENCES}

1. Ravi Kumar, M. N. Y.; Muzzarelli, R. A. A.Chemical Reviews, 2004, 104 (12), 60176084.

2. Jeuniaux, C. ;Vossfoucart, M. F. Biochemical Systematics and Ecology, 1991, 19 (5), 347356.

3. Srinivasa, P. C. ;Tharanathan, R. N. Food Reviews International, 2007, 23 (1), 53-72.

4. Annouar, S.; Soufiane, A.; Mountadar, M. Déchets - Revue Francophone d'écologie Industrielle, 2005, 37(1), 34-42.

5. Guibal, E. Progress in Polymer Scienc,.2005, 30 (1), 71-109.

6. Macquarrie,D. J.; Hardy, E. Industrial\& Engineering Chemistry Research, 2005, 44 (23), 8499-8520.

7. Travi.Y.; Cad. C. R. A. Sc. Paris, T. 298,1984, 2(7), 313-316.

8. B. A. Burt, O. Fejerskov., 2nd Edition,
ManksgaardTexbook, Copenhagen,1996, 275-290.

9. Dean,H. T. ; Jr, F. A.; Arnauld, E. Elvove. Public Health Report, 1942, 57, 1155-1179.

10. BurtB. A. and EklundS. A., Dentistry, Dental practice and the community, Philadelphie (Penns-ylvanie), W. B. Saunders Co, (1999).

11. Whitford, G. M. J. Dent. Res, 1990, 69, 539549.

12. SyM. H, Sene P, DioufM. M, DioufS., Fluorose osseuse au niveau de la main, Société d'Edition de l'Association d'Enseignement Médical des Hôpitaux de Paris, 1996, 15 (2), 109.

13. Mountadar, M. ; Garmes, H. ;Bouragi,A.;YousraniK. Association Scientifique Européenne pour l'Eau et la Santé, 2000, 5(1), 61-70.

14. Bhargava, D. S.; Killdeer, D. J. Water 
Research,1992, 26, 781-788.

15. Belle J.P. and Jersale C., T. S. M l'Eau 2,1984, 79, 87.

16. Mountadar, M.; Jemjami,S. Physical \& Chemical News, 2002, 8, 84-87.

17. Garmes,H.;Persin,F.;Sandeaux,J.;Pourcelly, G. ; Mountadar, M. Desalination, 2002, 145, 287-291.

18. Amor,Z.; Barioub,B.;Mamer,N.;Taky,M. ;Nicolasb,S.; El Midaoui, A. Desalination, 2001, 133, 215-223.

19. Pontie,M.; Buisson,H. ; Diawara,C. K.;Essitome, H. Desalination, 2003, 157, 127-134

20. Ryachi, K.; Bencheikh, A. Ann. Chim. Sci. Mat, 1998, 23,393-396.

21. Tolaimate,A. ;Desbriéres,J. ;Rhazi,M. ; Alagui,A.;Vincendon,M. ;Vottero, P. Polymer, 2000, 41, 2463-2469.

22. Tolaimate, A.;Desbriéres, J. ;Rhazi,M. ;Alagui, A.;Vincendon,M. ;Vottero.3 rdIntenational Conference of the European Chitin Society EUCHS'99, Potsdam, Germany, (1999).

23. Sehchi, M. ; Masaru, M. ; Reikichi, I. ; Susumu,
Y. Journal of appliedPolymer Sciences, 1983,28, 1909-1917.

24. Liu,X. D.; Tokura,S .; Haruki,M.; Nishi,N.; Sakairi, N.. Carbohydrate Polymers,2002, 49, 103-108.

25. Annouar S., Thèse de doctorat. Faculté des sciences. El Jadida.Maroc, (2005).

26. KHAYAT BIZRI,Y.; BIZRI,M. Association Scientifique Européenne pour l'Eau et la Santé, 1999,4( 1), 15-22.

27. AFNOR., Recueil des normes françaises: qualité de l'eau", $3^{\text {ème }}$ édition, (1999).

28. Annouar,S.;Mountadar,M.; A. Soufiane., Phys. Chem. News, 2004 , 16, 128-135

29. Annouar,S.;Soufiane,A. ;Mountadar, M. Déchets- Revue Francophone d'écologie Industriel, 2005, 37.

30. Jaafari, K.; Elmaleh,S.; Coma,J.;Benkhouja, K.Water S. A, 2001, 27( 1), 9-13.

31. BernardM., BurnotF., Usuel of genral and inorganic chimistry. Dunod, Paris, (1996).

32. JaafariK., Doctoral thesis. Fac. Sc. EL JadidaMorocco, (2001). 